\title{
Ashwagandha (Withania somnifera) - a herb with versatile medicinal properties empowering human physical and mental health
}

\author{
Sonu Gupta ${ }^{1, A-F}{ }^{\oplus}$, Ravinder Nath Bansal ${ }^{2, E}{ }^{\oplus}$, Surender Pal Singh Sodhi ${ }^{1, E}{ }^{\oplus}$, \\ Gursimrat Kaur Brar ${ }^{1, D \oplus}$, Mehak Malhotra',D $\odot$ \\ ${ }^{1}$ Dasmesh Institute of Research \& Dental Sciences, Faridkot, India \\ ${ }^{2}$ Guru Gobind Singh Medical Hospital, Delhi, India \\ A - Research concept and design, B - Collection and/or assembly of data, C - Data analysis and interpretation, \\ $D$ - Writing the article, E - Critical revision of the article, F - Final approval of the article
}

Gupta S, Bansal RN, Sodhi SPS, Brar GK, Malhotra M. Ashwagandha (Withania somnifera) - a herb with versatile medicinal properties empowering human physical and mental health. J Pre-Clin Clin Res. 2021; 15(3): 129-133. doi: 10.26444/jpccr/141582

\begin{abstract}
Introduction. Ashwagandha is a rasayana of Ayurveda system of medicines. It is a real potent regenerative tonic possessing several pharmacological properties like neuro-protective, anti-stress, anti-arthritic, antitumor, analgesic and anti-inflammatory. Objective. To illustrate applications and limitations of Ashwagandha in detail.

Materials and method. Data was collected from various review and research publications. Literature review involved animal studies and human studies. Emphasis was given on versatility of medicinal properties.

Results. Ashwagandha plays an important role in improving quality of life and performance at work and possess several pharmacologic actions. Each part of this herb i.e. from root to fruit possess medicinal properties.

Conclusions. Ashwagandha possesses wide variety of therapeutic uses in each and every system of human body. The plant has also been widely studied for its various pharmacological activities like antioxidant, anxiolytic, adaptogen, memory enhancing, antiparkinsonian, antiinflammatory, antitumor properties. Irrespective of such large network of benefits this herb has some limitations of use in certain situations.
\end{abstract}

\section{Key words}

Ashwagandha, active constituents, therapeutic uses, herb, Ayurveda

\section{Key message}

Ashwagandha being a natural herb possess numerous medicinal benefits for the human body. It can be easily cultivated in home lawns thereby increasing its socio-economical utility. The herb is enriched with many unidentified, unbelievable and miraculous properties

\section{INTRODUCTION}

Winter cherry, Indian ginseng, and Ajagandha, Queen of Ayurveda, called by so many names, Withania somnifera Dunal (Ashwagandha; Family-Solanaceae), is a plant used in ayurvedic medicine in the traditional system and indicated for the management of several neurological disorders. Ashwagandha (ASH) is a Rasayana of Ayurveda - a real potent regenerative tonic possessing several pharmacological properties, such as neuro-protective, anti-stress, anti-arthritic, antitumour, analgesic and anti-inflammatory [1]. Fresh root of the Ashwagandha herb 'smells like horse' so-called Ashwagandha, because there is the belief that anyone who consumes the herb is given the power and strength of a horse) $[1,2,3]$. It is also referred to as a 'royal herb' possessing multiple therapeutic effects in the different human body systems: immune system, neurological and endocrinal system, the aerobic energy-production system, as well as the reproductive system $[3,4]$. The presented study depicts the miraculous role of Ashwagandha in Ayurveda possessing versatile medicinal properties empowering human physical and mental health.

Address for correspondence: Ravinder Nath Bansal, Guru Gobind Singh Medical Hospital, Medical Campus, Faridkot, 1639, Faridkot, India

E-mail: RNbansal@gmail.com

Received: 05.05.2021; accepted: 25.08.2021; first published: 06.09.2021
Versatile roles of Ashwagandha. Ashwagandha as a whole plant including each part serves therapeutic uses (Table 1). Several therapeutic properties of ashwagandha are associated with presence of chemical consituents in the herb (Table 2). In the era of evidence-based medicine research and innovation is a practical phenomenon [5]. Ashwagandha has been also used successfully in ayurvedic research.

\section{Rasayana}

Ashwagandha as a herb promotes the health of body and brain by increasing stress tolerance and reinforcing the immune system. Ashwagandha is available as churna, a fine powder that can be mixed with water or ghee honey which has various medicinal benefits. It improves the memory and increases the function of the central nervous system (CNS) $[5,6]$. This miraculous benefit of the herb has been proved by a study in which the Morris water maze test was conducted to assess the effect of $W$. somnifera, where rats pre-treated with the herb showed significant alterations towards normal in comparison to control groups (disease group) [7-10]. The Morris water maze test and maze test were also used in a study to assess the effect of $W$. Somnifera on 3-NP (3-nitropropionic acid) induced Huntington's disease (HD) [11]. In both tests the Morris water maze and maze test, W. somnifera (100 and $200 \mathrm{mg} / \mathrm{kg}$ ) treatment for two 
Table 1. Benefits of individual part of Ashwagandha herb

\begin{tabular}{|c|c|c|c|}
\hline $\begin{array}{l}\text { Part of plant and } \\
\text { its applications }\end{array}$ & Active constituents & Therapeutic uses & Ref \\
\hline \multirow[t]{3}{*}{ Root } & \multirow[t]{3}{*}{$\begin{array}{l}\text { methanol, hexane and diethyl ether extracts, } \\
\text { alkaloid and steroids percentage in the roots are } \\
\text { reported to contain starch, reducing sugars, glycosides, } \\
\text { dulcitol, withancil, an acid and a neutral compound. } \\
\text { The amino acids reported from the roots include } \\
\text { aspartic acid, glycine. }\end{array}$} & $\begin{array}{l}\text { Regarded as a tonic, aphrodisiac, narcotic, diuretic, anthelmintic, astringent, } \\
\text { thermogenic and stimulant. It is commonly used in emaciation of children (when } \\
\text { given to children along with milk, it is the best tonic), debility from old age, } \\
\text { rheumatism, vitiated conditions of vata, insomnia, nervous breakdown, goiter, } \\
\text { leucoderma, constipation, etc. }\end{array}$ & \multirow[t]{5}{*}[2,8]{} \\
\hline & & $\begin{array}{l}\text { Also used as local application in carbuncles, ulcers and painful swellings } \\
\text { A paste is formed after crushing roots with water, which is applied to the joints to } \\
\text { reduce the inflammation. }\end{array}$ & \\
\hline & & $\begin{array}{l}\text { In combination with other drugs is also indicated for snake venom as well as in } \\
\text { scorpion-sting. It also useful for pimples, flatulent colic, worms, piles leucorrhoea and } \\
\text { boils }\end{array}$ & \\
\hline Leaves & $\begin{array}{l}\text { methanol, hexane and diethyl ether extracts, } \\
\text { Withaferin-A }\end{array}$ & Leaves taste bitter and are indicated in painful swellings and fever. & \\
\hline $\begin{array}{l}\text { Flowers and } \\
\text { seeds }\end{array}$ & $\begin{array}{l}\text { Ashwagandha Arishta prepared from seeds is used for } \\
\text { anxiety, memory loss, syncope, and hysteria. It also acts } \\
\text { as a stimulant, thus increasing the sperm count. }\end{array}$ & $\begin{array}{l}\text { Flowers are depurative, diuretic and aphrodisiac, astringent. } \\
\text { Seeds are anthelmintic and in combination with rock salts are useful in removing } \\
\text { white spots from the cornea }\end{array}$ & \\
\hline
\end{tabular}

Table 2. Chemical constituents of Ashwagandha

\begin{tabular}{|c|c|c|c|}
\hline Chemical constituent & Therapeutic role & Mechanism & Reference \\
\hline Triethylene glycol (TEG) & sleep induction. & TEG promotes physiological sleep i.e. naturally occurring sleep in healthy individuals. & [3] \\
\hline Withanolides & $\begin{array}{l}\text { anti-cancer activity, } \\
\text { neuroprotection and anti- } \\
\text { stress activity, recovery from } \\
\text { amnesia, anti-mutagenic. }\end{array}$ & $\begin{array}{l}\text { - slows down the growth of lung, colon, breast and cancer cells; } \\
\text { - acts as growth inhibitor in human tumour cell lines counteracting mutagenic effect; } \\
\text { - improves cellular immune response to mitogens; } \\
\text { - reverses paclitaxel- induced neutropenia; } \\
\text { - respected as a natural source of potent radiosensitizer in chemotherapy; } \\
\text { - useful in melanoma- induced metastasis. }\end{array}$ & \\
\hline Sitoindoside, withanolides & $\begin{array}{l}\text { protects cells from oxidative } \\
\text { damage and disease. }\end{array}$ & $\begin{array}{l}\text { - eliminates free radicals from immune syste; has a good effect in iron overload and lead } \\
\text { toxicity; } \\
\text { - prevents neuroleptic- induced extra-pyramidal side-effects; } \\
\text { - increases natural antioxidants in the brain; } \\
\text { - stimulates the immune system through nitric oxide production in macrophage. }\end{array}$ & \\
\hline $\begin{array}{l}\text { Sitoindoside VII and } \\
\text { sitoindoside VIII, sitoindoside } \\
\text { IX and X }\end{array}$ & $\begin{array}{l}\text { anti-stress activity, stress- } \\
\text { induced gastric ulcer. }\end{array}$ & $\begin{array}{l}\text { - used as ginseng in chronic stress models; } \\
\text { - protects from stress- induced neuronal degeneration; } \\
\text { - helps in achieving a better state to fight against stress. } \\
\text { - prevents stress-related ulcer. }\end{array}$ & \\
\hline Sitoindoside IX and X & $\begin{array}{l}\text { immunomodulatory and } \\
\text { central nervous system } \\
\text { effects with impact on } \\
\text { memory, stress and learning. }\end{array}$ & $\begin{array}{l}\text { used as Medhya Rasayanas Medhya (mind and mental/intellectual capacity) this cognition- } \\
\text { promoting action of the herb as Medhya Rasayanas is observed best in cases of compromised } \\
\text { memory post head injury, or after prolonged illness, and in geriatrics or in case of children }\end{array}$ & \\
\hline $\begin{array}{l}\text { Glycowithanolides withaferin- } \\
\text { A and sitoindosides VII-X } \\
\text { isolated from the roots }\end{array}$ & $\begin{array}{l}\text { significantly reversed } \\
\text { ibotenic acid induced } \\
\text { cognitive defects. }\end{array}$ & $\begin{array}{l}\text { L-dopa found in Ashwagandha enhances memory via cholinergic channels; stabilizes mood } \\
\text { and improves learning ability. }\end{array}$ & {$[2,8]$} \\
\hline
\end{tabular}

weeks significantly restored 3-NP induced memory loss. Neurodegenerative disorders cause memory loss and $W$. Somnifera has been found to improve learning ability with potential protection against memory loss. In one study, the effect of the herb on cognitive dysfunction induced by reserpine was investigated by using plus maze learning task Withania somnifera root extract (50 and $100 \mathrm{mg} / \mathrm{kg} /$ day for one month) significantly improved the long-term memory and learning ability in reserpine-treated animals, compared to those treated only with reserpine $[12,13]$

Withania somnifera leaf extract has been found to ease cognitive dysfunction by showing improved hippocampal plasticity in a high fat diet (HFD) induced obesity model. Ashwagandha has been found to significantly improve working memory by preventing the memory related cognitive impairments and locomotor coordination in high fat diet rats. During locomotor coordination studies it was observed that HFD rats showed deficiency in interest and strength, whereas
ASH treated low fat diet extract (LFDE) and high fat diet extract (HFDE) rats performed similarly to low fat diet (LFD) rats, indicating their normal neuromuscular coordination. Findings from the behavioural studies revealed that HFD regimen caused locomotor and neuro-muscular dysfunction, and ASH proved the potential to improve motor performance and body balance in rats on an HFD regimen [14].

During the novel drug development process, assessment of drug effects on psychomotor performance is truly essential. In clinical pharmacological studies psychometric tests are performed to quantitatively document the CNS effects of drugs. Effects of drugs on the central nervous system (CNS) can be assessed in the form of effects on attention, vigilance, cognition, behaviour, and neuro-physiological activity of the brain. Withania somnifera improves the brain's cognitive capabilities by increasing the capability of muscarinic receptors [15]. Pingali et al. demonstrated favourable effects of Withania somnifera aqueous extract on cognitive and 
Table 3. Diseases affecting quality of life with ICD code and therapeutic effects of Ashwagandha

\begin{tabular}{|c|c|c|c|}
\hline Diseases affecting quality of life and work performance & ICD CODE & Therapeutic effects of ashwagandha & Reference \\
\hline Insomnia & G47.00 & TEG in Ashwagandha is able to generate sleep more frequently. & {$[3,21-25]$} \\
\hline Osteoarthritis & M19 & protects against inflammation and cartilage damage associated with osteoarthritis. & \\
\hline Type 2 diabetes & E11 & helps normalize high blood sugar and improves insulin sensitivity & \\
\hline
\end{tabular}

psychomotor performance in healthy human participants in which several psychometric tests were performed using a computerized psychometric test system [16]. Withania somnifera has been found to modulate the neuro-endocrinoimmune system and is known as brain tonic rich in antioxidants, especially in the field of Ayurveda. Clinical trials have proved the anti-depressant activity of the herb without causing any sedative effect. It eases the mental stress bundle with resultant optimization of mental and psychomotor performance [17]

Sitoindosides VII-X and withaferin-A derived from leaf and fruit extracts of Withania somnifera has been found to increase cortical muscarinic acetylcholine capacity by its cognition-enhancing effect, as seen in animal models and humans [15] It was found in a randomized, double-blind study that Withania somnifera showed improved psychomotor performance in healthy participants with significant improvement in integrated sensorimotor function, auditory reaction tim, as well as mental arithmetic as compared to Panax ginseng and placebo in 30 healthy volunteers [18].

\section{Adaptogen}

Ashwagandha acts as a plant which helps the body to adapt to stress in order to correct the imbalance among immune and neuroendocrine system. It normalizes the body functions affected by the influence of stress by targetingthe hypothalamic-pituitary-adrenal gland axis. Ashwagandha decrease cortisol levels in a person under chronic stress, restoring the healthy adrenal function and thus normalizing the sympathetic nervous system [3]

Somnifera (sleep-inducing). In a study of effect of alcoholic and water extracts of Ashwagandha leaves on the quality and quantity of sleep, significant electroencephalogram (EEG) and electromyogram (EMG) changes were seen in an animal model (mice). Ayurveda, the traditional medicine system of India, also supported that an increase in sleep was observed after administration of extracts from leaf and root in rats, and after oral consumption of the powder obtained from root, leaves or whole plant in humans. Tri-ethylene Glycol (TEG), an active component of Ashwagandha leaves, is a potent sleep-inducing small molecule. Sleep regulation has two components viz sleep generation, i.e. frequency of NREM episodes and sleep maintenance duration NREM episodes. TEG is able to generate sleep more frequently, thus increasing the total amount of NREM sleep. TEG also promotes physiological sleep, i.e. naturally occurring sleep in healthy individuals. TEG was found to increase the frequency of NREM sleep episodes, which suggests that it has a potential to generate sleep via targeting the sleep generation mechanism [3].

\section{Ojas}

Ojas is the end condition of properly digested healthy food, and the most refined level of the physical body in contrast to 'Ojakshaya' (decreased Ojas) which refers to a condition similar to AIDS/HIV. Ojas is responsible for a healthy immune system, physical strength, clarity of mind and sense of well-being. It allows consciousness to flow within the body. Ashwagandha enhances Ojas. Ashwagandha in the form of churna when used on a regular basis helps to improve conditions like senile debility, rheumatism, general debility, nervous exhaustion, brain-fog, low memory, loss of muscular energy and spermatorrhoea. It increases vigour and body energy and helps in rebuilding the body system worn-out as a result of chronic diseases like syphilis and rheumatism [19].

Improving the quality of life. Ashwagandha plays an important role in improving the quality of life and performance at work. These diseases affecting the quality of life are mentioned in table. 3 along with International Classification of Diseases (ICD) code [20] and various pharmacologic actions and interactions of Ashwagandha are listed in Table 4.

Effects of Ashwagandha observed in other conditions. Male sexual dysfunction: Ashwagandha root extract is used to treat sexual weakness, erectile dysfunction, and sexual performance anxiety in men.

Immunostimulation - immunity stimulating effect through macrophages. Raised antibody titer against Bordetella pertusis strains (combats diphtheria).

Reproductive action and rejuvenating effect - increases libido and sexual function. Supports the female reproductive system, increases ovarian weight and folliculogenesis; a rejuvenative herb in the Indian herbal system

Ashwagandha as a cardiovascular protector protects the cardiovascular system against ischemic and reperfusion injury; useful in focal ischemia, supports anti-atherogenic activity in polyherbal formula $[21,32]$.

Pharmacological interactions of Ashwagandha. Pregnancy - safety in pregnancy has not been yet fully established for Ashwagandha. Ashwagandha has been reported to be a cause of abortions; therefore pregnant women should not use this herb. It should also not be used with other sedatives or anti-anxiety drugs. Even higher doses are observed to be related with stomach upset, diarrhea and vomiting. However, Ashwagandha does not have any significant side-effects· [21] and has been found to possess pharmacologic interactions listed in Table 5. 
Table 4. Pharmacological Actions of Ashwagandha

\begin{tabular}{ll}
\hline Pharmacologic action & Findings from preclinical studies \\
\hline Anxiolytic effect & $\begin{array}{l}\text { Ashwagandha and lorazepam reduced brain levels of tribulin (an endocoid marker of clinical anxiety) in rats following } \\
\text { administration of the anxiogenic agent pentylenetetrazole which raises the levels. }\end{array}$ \\
\hline Anti-depressant effect & $\begin{array}{l}\text { Anti-depressant effect is comparable to the effect produced by imipramine, in learned helplessness and forced swim-induced } \\
\text { 'behavioural despair' tests. }\end{array}$ \\
\hline $\begin{array}{l}\text { Gaba-mimetic effect on } \\
\text { neurodegeneration and } \\
\text { neuroregenerative potential }\end{array}$ & $\begin{array}{l}\text { The herb, its constituents and metabolites of its constituents promote the growth of nerves after consumption for a week. } \\
\text { Induction of axon and dendrite outgrowth, thereby resulting in neuritis regeneration and synaptic reconstruction }\end{array}$ \\
\hline Anti-Parkinson's effect & $\begin{array}{l}\text { Pre-treatment with Ashwaganda extract was found to protection of the neuronal injury in parkinson's disease in a dose- } \\
\text { dependent manner }\end{array}$ \\
\hline Analgesic activity & $\begin{array}{l}\text { Ashwagandha (1000 mg/kg/oral) produced significant analgesic activity in a rat experiencing heat analgesia induced by hot } \\
\text { plate method. }\end{array}$ \\
\hline Acute toxicity studies & LD50 of Withania somnifera was found to be 1750 mg (p.o.) in albino mice. \\
\hline Anti-tumour effect & $\begin{array}{l}\text { Effect on Chinese Hamster Ovary (CHO) cells carcinoma. Ashwagandha inhibits cell growth and prevents cell attachment. } \\
\text { Inhibitory effect of Withania roots was observed in up to 49\% on the colony forming efficiency of CHO cells, dependent on the } \\
\text { cell density and duration of Ashwagandha exposure. }\end{array}$ \\
\hline
\end{tabular}

Table 5. Pharmacologic interactions of Ashwagandha

\begin{tabular}{|c|c|c|c|c|c|}
\hline Ashwagandha interaction type & Effects observed & Clinical evidence & $\begin{array}{l}\text { Experimental } \\
\text { evidence }\end{array}$ & Mechanism & Reference \\
\hline Anti-diabetic & $\begin{array}{l}\text { blood-glucose lowering } \\
\text { effects } \\
\text { which may be additive with } \\
\text { conventional } \\
\text { anti-diabetics }\end{array}$ & Present & No interactions found. & Not known & {$[26-31]$} \\
\hline $\begin{array}{l}\text { Ashwagandha }+ \text { methods of } \\
\text { measuring serum digoxin } \\
\text { levels }\end{array}$ & $\begin{array}{l}\text { digoxin levels might be spuriously } \\
\text { elevated when assayed using } \\
\text { a fluorescence polarisation } \\
\text { immunoassay in patients taking }\end{array}$ & No interactions found & Present & $\begin{array}{l}\text { Known. Some withanolides (major } \\
\text { constituents of ashwagandha) are } \\
\text { structurally } \\
\text { similar to digoxin, and might } \\
\text { therefore interfere with the } \\
\text { digoxin immunoassay }\end{array}$ & \\
\hline $\begin{array}{l}\text { Ashwagandha + Laboratory } \\
\text { tests }\end{array}$ & $\begin{array}{l}\text { no interference with in vitro } \\
\text { assays for carbamazepine, } \\
\text { gentamicin, paracetamol, } \\
\text { phenytoin phenobarbital, } \\
\text { procainamide, salicylate, } \\
\text { theophylline, tobramycin } \\
\text { or valproic acid }\end{array}$ & No interactions found & No interactions found & No & \\
\hline Ashwagandha + Food & -- & No interactions found & No interactions found & no & \\
\hline $\begin{array}{l}\text { Ashwagandha }+ \text { herbal } \\
\text { medicines }\end{array}$ & --- & No interactions found & No interactions found & no & \\
\hline $\begin{array}{l}\text { Ashwagandha + thyroid and } \\
\text { anti-thyroid drugs }\end{array}$ & $\begin{array}{l}\text { increases thyroid } \\
\text { hormone levels and found to } \\
\text { interfere with the control of hypo- } \\
\text { and hyperthyroidism }\end{array}$ & Present & Present & Unknown & \\
\hline
\end{tabular}

\section{CONCLUSIONS}

Ashwagandha is a plant used in Ayurveda, the ancient system of Indian medicine. Ashwagandha is a rasayana, adaptogen as well as nervine tonic. The plant has also been widely studied for its various pharmacological activities, such as antioxidant, anxiolytic, adaptogen, memory enhancing, anti-parkinsonian, ant-inflammatory, anti-tumour properties. Various other effects, e.g. immunomodulation, hypolipidaemic, antibacterial, cardiovascular protection, and sexual behaviour have also been studied. Although the effects of the herb are quite promising for use as a multi-purpose medicinal agent, several limitations exist in the current literature. There is a need to explore more about the herb, and more clinical trials are required to support its safe therapeutic use.

\section{REFERENCES}

1. Ray C, et al. Evaluation of neuro-protective activity of Ashwagandha and vacha in combination as ayurvedic medhya rasayana in vivo. Int Ayurvedic Med J. 2016; 4(10): 2914-22. http://www.iamj.in/posts/ images/upload/2914_2922.pdf.

2. Singh N, Bhalla M, de Jager P, et al. An overview on Ashwagandha: a Rasayana (rejuvenator) of Ayurveda. Afr J Tradit Complement Altern Med. 2011; 8(5): 208-213. doi: 10.4314/ajtcam.v8i5S.9. https://www.ncbi. nlm.nih.gov/pubmed/22754076

3. Kaushik MK, Kaul SC, Wadhwa R, et al. Triethylene glycol, an active component of Ashwagandha (Withania somnifera) leaves, is responsible for sleep induction. PLoS One. 2017; 12(2): e0172508. https://www.ncbi. nlm.nih.gov/pubmed/28207892

4. Gautam A, Wadhwa R, Thakur MK. Assessment of Cholinergic Properties of Ashwagandha Leaf-Extract in the Amnesic Mouse Brain. Ann Neurosci. 2016; 23(2): 68-75. doi: 10.1159/000443573. https://www. karger.com/Article/Fulltext/443573 
5. Gupta S, Bansal RN, Sodhi SPS, et al. Patent: A Journey From Idea to Patent. Inn Internat J Sci. 2018; 5(6): 5-11. https://www.innoriginal. com/index.php/iijs/article/view/209/pdf_1.

6. Gupta S. True pain of false healing - various treatment modalities (a research perspective). J Ayurveda Holistic Med. 2018; 6(1): 38-50. http:// www.jahm.in/index.php/JAHM/article/view/732

7. Baitharu I, et al. Withania somnifera root extract ameliorates hypobaric Feb hypoxia induced memory impairment in rats. J Ethnopharmacol. 2013; 145: 431-441.

8. Ahmed ME, et al. Attenuation of oxi-dative damage-associated cognitive decline by Withania somnifera in rat model of streptozotocin-induced cognitive impairment. Protoplasma 2013; 250: 1067-1078.

9. Sehgal N, et al. Withania somnifera reverses Alzheimer's disease pathology by enhancing low-density lipoprotein receptor-related protein in liver. Proc Natl Acad Sci. USA 2012; 109: 3510-3515.

10. Parkash J, et al. Neuroprotective role of Withania somnifera root extract in Maneb-Paraquat induced mouse model of Parkinsonism. Neurochemis Res. 2013; 38: 972-980.

11. Kumar P, Kumar A. Effects of root extract of Withania somnifera in 3-Nitropropionic acid-induced cognitive dysfunction and oxidative damage in rats. Int J Health Res. 2008; 1: 139-149.

12. Durga S, Dhaddea SB, Vandalb R, et al. Withania somnifera (Ashwagandha) in neurobehavioural disorders induced by brain oxidative stress in rodents: a systematic review and meta-analysis. J Pharm Pharmacol. 2015; 67: 879-899.

13. Naidu PS, et al. Effect of Withania somnifera root extract on reserpineinduced orofacial dyskinesia and cognitive dysfunction. Phytother Res. 2006; 20: 140-146.

14. Manchanda S, Kaur G. Withania somnifera leaf alleviates cognitive dysfunction by enhancing hippocampal plasticity in high fat diet induced obesity model. BMC Complement Altern Med. 2017; 317(1):136. doi: 10.1186/s12906-017-1652-0

15. Schliebs R, et al. Systemic administration of defined extracts from Withania somnifera (Indian Ginseng) and Shilajit differentially affects cholinergic but not glutamatergic and GABAergic markers in rat brain. Neurochem Int. 1997; 30: 181-90.

16. Pingali U, Pilli R, Fatima N. Effect of standardized aqueous extract of Withania somnifera on tests of cognitive and psychomotor performance in healthy human participants. Pharmacognosy Res. 2014; 6(1): 12-18. doi: 10.4103/0974-8490.122912. https://www.ncbi.nlm.nih.gov/pmc/ articles/PMC3897003/

17. Gupta GL, Rana AC. Withania somnifera (Ashwagandha): A review. Pharmacogn Rev. 2007; 1: 129-36.

18. Karnick CR. A double-blind, placebo-controlled clinical studies on the effects of Withania somnifera and Panax Ginseng Extracts on psychomotor performance in healthy Indian volunteers. Indian Med. 1991; 3: 1-5.

19. Jana1 SN, Charan SM. Health Benefits and Medicinal Potency of Withania somnifera: A Review. Int J Pharm Sci Rev Res. 2018; 48(1): 22-29. http://globalresearchonline.net/journalcontents/v48-1/08.pdf
20. Reed GM, First MB, Kogan CS, et al. Innovations and changes in the ICD-11 classification of mental, behavioural and neurodevelopmental disorders. World Psychiatry. 2019; 18(1): 3-19. doi: 10.1002/wps.20611 21..Umadevi M, Rajeswari R, Rahale CR, et al. Traditional and Medicinal Uses of Withania Somnifera. Pharma Innov. 2012; 1(9): 102-10. http:// www.thepharmajournal.com/vol1Issue9/Issue_nov_2012/11.1.pdf

22.2020 ICD-10-CM Diagnosis Code G47.00. Insomnia, unspecified [accessed 2019 june]..https://www.icd10data.com/ICD10CM/Codes/ G00-G99/G40-G47/G47-/G47.00

23. https://icd.codes/icd10cm/M199 [accessed 2019 june 16].

24.2020 ICD-10-CM Diagnosis Code F41.Other anxiety disorders [accessed 2019 june 16] https://www.icd10data.com/ICD10CM/Codes/F01-F99/ F40-F48/F41-

25.2020 ICD-10-CM Diagnosis Code E11.Type 2 diabetes mellitus [accessed 2019 june 16] https://www.icd10data.com/ICD10CM/Codes/E00-E89/ E08-E13/E11-/E11

26. Andallu B, Radhika B. Hypoglycemic, diuretic and hypocholesterolemic effect of winter cherry (Withania somnifera, Dunal) root. Indian J Exp Biol. 2000; 38: 607-9. https://pdfs.semanticscholar.org/e446/878b7811 c969a9b63e7dec6920137140bb35.pdf

27. Dasgupta A, Peterson A, Wells A, et al. Effect of Indian Ayurvedic medicine Ashwagandha on measurement of serum digoxin and 11 commonly monitored drugs using immunoassays: study of protein binding and interaction with Digibind. Arch Pathol Lab Med. 2007; 131: 1298-1303. https://pdfs.semanticscholar.org/48ca/ b2c45815b1d766caf4561fa8253a7ec972a3.pdf

28. Dasgupta A, Kang E, Olsen M, et al. Interference of Asian, American, and Indian (Ashwagandha) ginsengs in serum digoxin measurements by a fluorescence polarization immunoassay can be minimized by using a new enzyme-linked chemiluminescent im munosorbent or turbidimetric assay. Arch Pathol Lab Med. 2007; 131: 619-21. https:// www.ncbi.nlm.nih.gov/pubmed/17425395

29. Dasgupta A, Reyes MA. Effect of Brazilian, Indian, Siberian, Asian, and North American ginseng on serum digoxin measurement by immunoassays and binding of digoxin-like mmunoreactive components of ginseng with Fab fragment of antidigoxin antibody (Digibind). Am J Clin Pathol. 2005; 124: 229-36. https://www.ncbi.nlm.nih.gov/ pubmed/16040294

30. Van der, Hooft CS, Hoekstra A, Winter A, de Smet PAGM, Stricker BHC. Thyroid toxicosis after using Ashwagandha. Ned Tijdschr Geneeskd. 2005; 149: 2637-8. https://www.ncbi.nlm.nih.gov/pubmed/16355578

31. Panda S, Kar A. Changes in thyroid hormone concentrations after administration of Ashwagandha root extract to adult male mice. J Pharm Pharmacol. 1998; 50: 1065-8. https://www.ncbi.nlm.nih.gov/ pubmed/9811169 Thyroid toxicosis after using Ashwagandha

32. Nasimi Doost Azgomi R, Zomorrodi A, Nazemyieh H, et al. Effects of Withania somnifera on Reproductive System: A Systematic Review of the Available Evidence. Biomed Res Int. 2018; 4076430: 1-17. https:// doi.org/10.1155/2018/4076430 